\title{
BIOCLIMATOLOGIA APLICADA À AVICULTURA
}

Sabrina Holz ${ }^{2}$, Luisa Carolina Baccin ${ }^{3}$, Ana Claudia Picotti Casagrande ${ }^{4}$, Késia Damaris de Azevedo $^{5}$, Jianice Pires Frigo ${ }^{6}$, Lucas dos Santos Dierings ${ }^{7}$

\footnotetext{
${ }^{1}$ Aceito para publicação no $1^{\circ}$ trimestre de 2014

${ }^{2}$ Acadêmicas do curso Superior de Agronomia, Universidade Federal do Paraná - UFPR, Setor Palotina - PR, Brasil, sabrinaholz16@gmail.com;

${ }^{3}$ Acadêmicas do curso Superior de Agronomia, Universidade Federal do Paraná - UFPR, Setor Palotina - PR, Brasil, luisa.cbio@gmail.com;

${ }^{4}$ Acadêmicas do curso Superior de Agronomia, Universidade Federal do Paraná - UFPR, Setor Palotina - PR, Brasil, anaacasagraande@gmail.com;

${ }^{5}$ Graduada em Tecnologia em Biotecnologia na Universidade Federal do Paraná, Palotina - PR, Brasil, kesia.damaris@gmail.com;

${ }^{6}$ Graduanda em agronomia na Universidade Regional Integrada do Alto Uruguai e das Missões - URI Campus de Santiago - RS, Brasil, jifrigo@yahoo.com;

${ }^{7}$ Acadêmico do Curso Superior de Agronomia, Universidade Federal do Paraná - UFPR. Setor Palotina - PR, Brasil, lucasdierings@live.com.
}

\section{Resumo}

No último ano o Brasil manteve sua posição de maior exportador mundial e de terceiro maior produtor de carne de frango. Deste modo avalia-se que a partir do momento em que implantaram-se novas tecnologias relacionadas a produção da avicultura, desde melhoramento genético ao uso de instalações adequadas este setor passou a ter maior força no mercado. Desde então se tornou um grande desafio manter a ambiência dos aviários relacionando fatores climáticos com desenvolvimento do animal buscando o bem-estar e alta produtividade. Portanto, objetivou-se realizar um levantamento bibliográfico descrevendo o comportando das aves, bem como os elementos que beneficiam a produção.

Palavras-chave: Fatores climáticos, instalações, aves.

\section{BIOCLIMATOLOGY APPLIED TO AVICULTURE}




\begin{abstract}
In the last year, Brazil maintained its position of biggest world's exporter and third biggest chicken meat producer. Thereby, we evaluate that, from the moment in which new technologies related to chicken production were implanted, from genetic improvement to appropriate installations, this department now became stronger in the market. Since then, it became a big challenge to keep the ambience of poultry houses relating climatic factors to animal development seeking animal welfare and high productivity. Therefore, the objective is to perform a bibliographical survey describing the birds behavior as well as the elements that benefit the production.
\end{abstract}

Keywords: Climatic factors, installations, birds

\title{
Introdução
}

A atividade avícola existiu durante toda a história como atividade familiar, a produção de frango caipira. Produzia-se para o consumo próprio e eventualmente os excedentes eram comercializados (EMBRAPA, 2013).

De acordo com Carmo (1999), com o passar do tempo em que implantaram novas tecnologias na produção, como melhoria genética, introdução de novas tecnologias, uso de instalações apropriadas, controle da alimentação e parcerias firmadas entre produtor e agroindústria a avicultura passou a ter maior importância (TAVARES, 2007).

A produção avícola é um setor que gera empregos e tem destaque principalmente em áreas do interior das regiões Sul e Sudeste, onde é uma das principais atividades econômicas (ASSOCIAÇÃO BRASILEIRA DE PROTEÍNA ANIMAL - ABPA, 2012).

O conforto dos animais, que até algum tempo atrás era visto como um problema secundário passou a ser tratado com grande preocupação, visto que quando expostos a estresse calórico, a resposta fisiológica dos animais para retornar a zona de conforto causa perdas na produção, seja em aves de corte ou de postura (GOMES, et al, 2011).

Um desafio para manter a produção animal são as mudanças e variações do clima, uma vez que as aves são homeotérmicas e sensíveis a pequenas alterações na temperatura do ambiente (DAMASCENO, et al, 2010).

Para Sindiavipar (2012), um dos critérios exigidos pelo selo Certified Humane Brasil, é um ambiente adequado para a criação das aves, onde o alojamento seja bem manejado e evite 
o contagio de doenças. Os produtores devem observar fatores como a quantidade de animais, condições de temperatura, iluminação e ventilação.

Deste modo, tendo em vista que há poucos estudos sobre este assunto, esta revisão bibliográfica tem que como objetivo levantar os fatores que ajudam no bem-estar das aves, como estruturação de um aviário e descrever o comportando das aves, bem como os elementos que beneficiam a produção.

\section{História e evolução da avicultura}

No Brasil, a avicultura industrial iniciou-se no final da década de 1950, substituindo antiga avicultura comercial. Essa criação tem características como alto grau de controle do processo biológico, facilitando o desenvolvimento do animal em condições não favoráveis (FREITAS e BERTOGLIO, 2001, apud ARAUJO et al, 2008).

Este setor se desenvolveu mundialmente a partir da segunda guerra mundial. Segundo a UBABEF (2012, citado por CALIXTO, L. \& OLIVEIRA, L.) o desenvolvimento ocorreu pela necessidade de enviar aos soldados que estavam na guerra, carne vermelha sendo assim necessário investir em outras opções como a carne de animais de pequeno porte. O início do desenvolvimento se deu com a importação de linhagens híbridas dos Estados Unidos, as quais eram mais resistentes e produtivas, o que aumentou a busca pelas mesmas.

A partir desse desenvolvimento da produção avícola, segundo Nogueira, et al, (2003) aumentaram-se os contratos de parceria firmados entre produtores e agroindústria, aumentando a produção e barateando o custo, diminuindo o preço o que fez aumentar o consumo doméstico da carne e o avanço em diversos mercados internacionais.

O desenvolvimento da avicultura proporcionou o desenvolvimento do setor agrícola, de indústria de rações, máquinas e equipamentos, indústria farmacêutica e pontos comerciais como supermercados (CALIXTO \& OLIVEIRA, 2012).

Uma pesquisa realizada com quase 3.000 famílias pela Associação Brasileira de Proteína Animal - UBABEF, em 2012, revelou que a carne de frango é uma unanimidade, sendo consumida em $100 \%$ dos lares pesquisados, superando as demais carnes. Ao mesmo tempo, 99\% das famílias informaram consumir ovos regularmente, outro exemplo da importância da avicultura para a alimentação de todos os brasileiros.

\section{Avicultura de corte e de postura}

Revista Brasileira de Energias Renováveis, v. 3, p. 24-32, 2013 
Segundo a União Brasileira de Avicultura em seu Relatório Anual de 2013 as exportações brasileiras de ovos resultaram-se em 26,8 mil toneladas em 2012, sendo caracterizado por um acréscimo de 61,2\% quando comparado a 2011. Outro dado obtido pelo (Instituto Brasileiro de Geografia e Estatística - IBGE, 2010) em 2008 a área de avicultura no Brasil, aumentou o plantel de galinhas de postura em 5,1\%.

Para se produzir um frango de corte com peso de abate que atenda todos os requisitos técnicos adequados, não se dispõe de muito tempo, portanto é indispensável ao produtor atender alguns requisitos a fim de produzir frangos maiores, com menos uso de ração, objetivando o lucro e um produto saudável (PEREIRA, 2004).

Além das características do ambiente, o empenho de alguns fatores de critério genético, alimentício ou relacionado ao manuseio, da maneira de criação dos animais e do modelo de estalagem, também podem ser determinantes no desenvolvimento da produção das aves seja de postura ou de corte. É importante também que as aves sejam de baixa mortalidade, resistência a doenças e principalmente alta taxa de postura para aquelas com esse fim, resultando em um retorno econômico (UNIÃO BRASILEIRA DE AVICULTURA - UBA, 2008).

Segundo Alves (2007), o bem-estar na produção animal está sendo muito discutido, aumentando a certeza dos consumidores de que os animais utilizados para produção de alimentos devem ser bem tratados.

Catalan (2010), afirma que quando as aves passam por algum estresse diário, seja por alojamento com altas densidades, número insuficiente de comedouros ou bebedouros e até uma dieta irregular, pode levá-las ao canibalismo.

Segundo Rocha (2008) essa prática pode ser evitada com a seguinte técnica, "a debicagem", onde ela consiste na remoção de parte do bico superior e inferior, feita geralmente com lâmina elétrica quente que corta e cauteriza o tecido do bico. Esta prática também ajuda para evitar o desperdício de ração, especialmente na fase de postura, que causa grandes prejuízos ao produtor.

Para acompanhar a uniformidade, o desempenho e a rentabilidade das aves, a manutenção correta dos registros diários é essencial, bem como para fazer a detecção precoce de possíveis problemas. Sendo importante que esses registros sejam colocados em cada galpão, onde incluem mortalidade por galpão e sexo, consumo diário de ração e água, temperaturas ideais, números de aves encaminhadas para abate, entre outros (MANUAL DE MANEJO DE FRANGOS DE CORTE - COBB, 2008). 


\section{Condição Ambiental e Estresse Térmico}

As aves são animais homeotermos, que dispõem de um centro termorregulador localizado no hipotálamo parte do celebro que é constituído por neurônios que respondem ao calor, e são processados quando a temperatura corporal aumenta impulsionando a resposta periférica. Quando houver um balanço positivo das atividades neuronais que respondem ao frio e ao calor e a produção de calor for igual à perda, haverá temperatura corporal estável. Os mecanismos que mantém a homeostase térmica em frangos são a radiação, convecção e evaporação (GOMES, et al, 2011).

Segundo Tinôco (1998), um ambiente para ser agradável as aves adultas deve apresentar umidade relativa do ar de 50 a $70 \%$ e temperaturas de 16 a $23{ }^{\circ} \mathrm{C}$, então dificilmente estes valores serão encontrados em época de verão vigoroso e condições comercias de produção (OLIVEIRA, et al, 2006).

Conforme Baeta \& Souza (1997), esses dois elementos climáticos, são ligados ao conforto térmico animal, quando a temperaturas muito elevadas o meio de desperdiçar calor das aves é a evaporação, que depende da umidade relativa do ar (OLIVEIRA,et al, 2006).

No frio o frango de corte usa de um processo fisiológico para manter a homeotermia corporal, com a participação da musculatura através do aumento na produção de calor vinculada aos processos vitais, ao tremor muscular e à redução na taxa de perda de calor corporal para o meio (GOMES, et al, 2011).

Segundo Navarini (2009), a temperatura do ambiente pode ser considerada o fator físico de maior efeito no desempenho do frango, por exercer grande influência também no consumo de ração, assim afetando diretamente o ganho de peso e a conversão alimentar, já que durante o estresse por calor, há uma redução na eficiência de utilização de alimentos (GOMES, et al, 2011).

A zona de conforto térmico é a faixa de temperatura do ambiente na qual a taxa metabólica é mínima, e a temperatura do corpo do animal é mantida com muito pouco desprendimento de energia (FURLAN, 2006).

\section{Ambiência e Construção do aviário}

O ambiente de criação das aves é de fundamental importância no desenvolvimento do setor. A avicultura de corte tem investido hácerca de 20 anos em modificações das tecnologias, desenvolvendo um novo conceito na criação de aves. Técnicas têm sido aplicadas levando em

Revista Brasileira de Energias Renováveis, v. 3, p. 24-32, 2013 
consideração os aspectos climáticos e as necessidades dos animais, e conciliando conforto térmico e o bem-estar animal com a diminuição do tempo de criação, gerando aumento de produtividade (ABREU \& ABREU, 2011; AMARAL, et al, 2011).

A climatologia, que segundo Pédelaborde (1970), estuda os caracteres da atmosfera em contato com a superfície terrestre e a distribuição espacial desses caracteres, quando aplicada às relações com os seres vivos denomina-se bioclimatologia, podendo se distinguir como bioclimatologia humana, animal ou vegetal. Pretende-se com a arquitetura bioclimática aperfeiçoar o conforto ambiental no interior da construção (LANHAM, GAMA \& BRAZ, 2004).

É necessário realizar um levantamento microclimático da região a se construir um galpão. Aves apresentam redução na ingestão de alimento quanto expostas à altos índices de temperatura e as instalações podem afetar a troca térmica do animal com o ambiente (ABREU \& ABREU, 2011).

Ocorrem no Brasil, como citam Damasceno, et al (2010), ondas de calor, além das altas temperaturas durante o ano, típico de climas quentes e úmidos, o que faz com que as temperaturas dentro do abrigo causem estresse aos animais. Ainda segundo o autor, o problema na criação e aves devido a altos valores de temperatura do ar fica ainda mais complexo, pela diminuição da disponibilidade de água e alimento. A climatização do ambiente é uma saída eficiente, como equipamentos de ventilação, exaustão, nebulização e painéis de resfriamento adiabático.

Em períodos de baixa temperatura é necessário evitar perda de calor para fora do aviário, portanto controlar as aberturas é fundamental e importante, já por outro lado a ventilação tem uma função significativa, principalmente por razões higiênicas, renovando o ar interno, controlando a concentração de gases, poeira e vapor de água produzido (TINÔCO, 2001; NÃ̃̃S, et al, 2007, apud MENEGALI et al, 2009).

A qualidade do ar é extremamente importante na criação de aves. As trocas de ar inadequadas aumentam as concentrações gases no interior das instalações que diminuem a concentração de oxigênio, deixando o ambiente propício a incidência de doenças no trato respiratório, tanto nos animais quanto nos funcionários (ALENCAR, et al, 2001; OWADA et al, 2007, apud MENEGALI, et al, 2009)

No estudo de emissões de amônia Miragliotta (2000), citado por Nããs, et al, (2007) encontrou maiores concentrações do gás no ar e maior índice de condenação em sistemas de produção de alta densidade. 


\section{Considerações Finais}

Frente ao que foi discutido pode-se notar que um bom planejamento da estruturação de um aviário é de fundamental importância não só apenas para a manutenção do ambiente devido a fatores como variações climáticas em determinados períodos dos anos, mas também na melhor condição de criação do animal, proporcionando sempre uma melhor condição para o seu desenvolvimento. 


\section{Referências Bibliográficas}

ABREU, V. M. N.; ABREU, P. G. Os desafios da ambiência sobre os sistemas de aves no Brasil.R. Bras. Zootec., v.40, p.1-14, 2001.

ALVES, S. P.; SILVA, I. J. O. \& PIEDADE, S. M. S. Avaliação do bem-estar de aves poedeiras comerciais: efeitos do sistema de criação e do ambiente bioclimático sobre o desempenho das aves e a qualidade de ovos. ESALQ/USP. Piracicaba - SP. 2007.

AMARAL, A.G., et al. Efeito do ambiente de produção sobre frangos de corte sexados criados em galpão comercial. Arq. Bras. Med. Vet. Zootec., v.63, n.3, p.649658, 2011.

ARAÚJO, G. C.; BUENO, M. P. BUENO, V. P. et al. Cadeia produtiva da avicultura de corte: avaliação da apropriaçãode valor bruto nas transações econômicas dos agentes envolvidos. 2008.

BAÊTA, F.C.; SOUZA, C.F. Ambiência em edificações rurais, conforto animal. Viçosa, MG: Universidade Federal de Viçosa,1997.

CALIXTO, L. \& OLIVEIRA, L. T. D. A avicultura como atividade satisfatória para pequenos produtores com o sistema integrado de produção em um município do norte do Paraná. Universidade Estadual do Norte do Paraná. Cornélio Procópio. 2012.

CATALAN, A. A. S. \& MORAES, D. O. Manejo de aves poedeiras comerciais cria e recria. Universidade Federal de Pelotas - UFPel. Chapecó. 2010.

COBB. Manual de manejo de frangos de corte. 2008. Disponível em: <8TTP://wp.ufpel.edu.br/avicultura/files/2012/04/Cobb-Manual-Frango-Corte-BR.pdf> Acesso em: 20/05/2014.

DAMASCENO, F.A. et al. Mudanças climáticas e sua influência na produção avícola. PUBVET, Londrina, V. 4, N. 28, Ed. 133, Art. 901, 2010.

EMBRAPA. A avicultura no Brasil. 2013. Disponível em $<$ http://www.cnpsa.embrapa.br/cias/index.php?option=com_content\&view=article\&id= 13\&Itemid=15> Acesso em 20/05/2014.

FURLAN, R. L. Influencia da Temperatura na Produção de Frangos de Corte.VII Simpósio Brasil sul de avicultura - Chapecó, SC - Brasil. 2006.

GOMES, J.S. et al. Estresse Térmico na Avicultura. 2011. Disponível <http://fio.edu.br/cic/anais/2011_x_cic/PDF/Medicinaveterinaria/ESTRESSE\%20TER MICO\%20NA\%20AVICULTURA.pdf> Acesso em: 20/05/2014.

LANHAM, A. L.; GAMA, P. \& BRAZ, R. Arquitetura Bioclimática Perspectivas de inovação e futuro. Universidade Técnica de Lisboa, 2004.

MENEGALI, I., et al. Ambiente térmico e concentração de gases em instalações para frangos de corte no período de aquecimento. Revista Brasileira de Engenharia Agrícola e Ambiental. v.13, (Suplemento), p.984-990, 2009.

NÃÃS, I. de A. et al. Ambiência aérea em alojamento de frangos de corte: poeira e gases. Eng. Agríc. vol.27 no.2 Jaboticabal. 2007. 
NAVARINI, F.C. Níveis de Proteína Bruta e Balanço Eletrolítico para Frangos de Corte. 2009. Universidade Estadual do Oeste do Paraná, Marechal Cândido Rondon, 2009.

NOGUEIRA, A. C. L., et al. Coexistência de arranjos institucionais na avicultura de corte do estado de São Paulo. USP - Faculdade de Economia, Administração e Contabilidade. 2003.

OLIVEIRA, R. F. M. et al. Efeitos da temperatura e da umidade relativa sobre o desempenho e o rendimento de cortes nobres de frangos de corte de 1 a 49 dias de idade. R. Bras. Zootec., v.35, n.3, p.797-803, 2006.

PEREIRA, V. L. A. Qualidade de frangos de corte ao abate pela relação entre peso, doença de gumboro e algumas enfermidades associadas. Universidade Federal Fluminense. 2004.

ROCHA, J. S. R.; LARA, L. J. C. \& BAIÃ, N. C. Produção e bem-estar animal: Aspectos éticos e técnicos da produção intensiva de aves. Escola de Veterinária UFMG. 2008.

SINDIAVIPAR. Cooperativismo de resultados. Avicultura PR, ano V, n 28, 2012.

TAVARES, L. de P. \& RIBEIRO, K. C. de S. Desenvolvimento da avicultura de corte brasileira e perspectivas frente à influenza aviária. Organizações Rurais \& Agroindustriais, Lavras, v. 9, n. 1, p. 79-88, 2007.

UBA. União Brasileira de Avicultura. Protocolo de boas práticas de produção de ovos. São Paulo. Junho/2008. Disponível em: <http://www.avisite.com.br/legislacao/anexos/protocolo_de_boas_praticas_de_produca o_de_ovos.pdf> Acesso em: 20/05/2014.

UBA. União Brasileira de Avicultura. Relatório Anual. 2013. Disponível em <http://www.ubabef.com.br/publicacoes> Acesso em 20/05/2014.

UBABEF. Associação Brasileira de Proteína Animal. História da avicultura no Brasil. 2012.

Disponível

em:

<http://www.ubabef.com.br/a_avicultura_brasileira/historia_da_avicultura_no_brasil > Acesso em: 20/05/2014. 